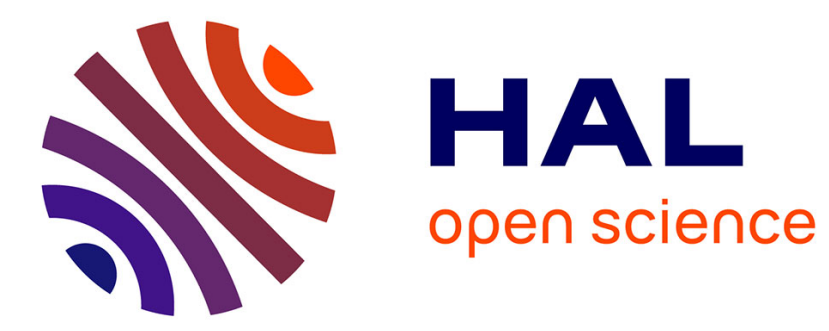

\title{
Influence of isothermal aging conditions on APS TBC's interfacial fracture toughness
}

Yankuan Liu, Yinghui Liu, Philippe Lours, Thierry Sentenac, Vanessa Vidal, Zhiping Wang, Kunying Ding

\section{- To cite this version:}

Yankuan Liu, Yinghui Liu, Philippe Lours, Thierry Sentenac, Vanessa Vidal, et al.. Influence of isothermal aging conditions on APS TBC's interfacial fracture toughness. Surface and Coatings Technology, 2017, 313, pp.417-424. 10.1016/j.surfcoat.2017.01.008 . hal-01662699

\section{HAL Id: hal-01662699 \\ https://hal.science/hal-01662699}

Submitted on 7 Dec 2018

HAL is a multi-disciplinary open access archive for the deposit and dissemination of scientific research documents, whether they are published or not. The documents may come from teaching and research institutions in France or abroad, or from public or private research centers.
L'archive ouverte pluridisciplinaire HAL, est destinée au dépôt et à la diffusion de documents scientifiques de niveau recherche, publiés ou non, émanant des établissements d'enseignement et de recherche français ou étrangers, des laboratoires publics ou privés. 


\title{
Influence of isothermal aging conditions on APS TBC's interfacial fracture toughness
}

\author{
Yankuan Liu ${ }^{\mathrm{a}, *}$, Yinghui Liu ${ }^{\mathrm{b}}$, Philippe Lours ${ }^{\mathrm{b}}$, Thierry Sentenac ${ }^{\mathrm{b}}$, Vanessa Vidal ${ }^{\mathrm{b}}$, \\ Zhiping Wang ${ }^{a}$, Kunying Ding ${ }^{a}$ \\ a Tianjin Key Laboratory of Civil Aircraft Airworthiness and Maintenance, Civil Aviation University of China, Tianjin, China \\ ${ }^{\mathrm{b}}$ Université de Toulouse, CNRS, Mines Albi, INSA, UPS, ISAE, ICA (Institut Clément Ader), Campus Jarlard, F-81013 Albi, France
}

\begin{abstract}
A B S T R A C T
Interfacial toughness is an important factor to address thermal barrier coating's (TBC) durability. In this paper, a promising method, based on interfacial indentation, is used to analyze apparent interfacial toughness of TBC deposited by Atmospheric Plasma Spray (APS). The specimens made by APS were treated using different oxidation holding times and temperatures, namely $1050{ }^{\circ} \mathrm{C}-100 \mathrm{~h}, 1100{ }^{\circ} \mathrm{C}-100 \mathrm{~h}, 1050{ }^{\circ} \mathrm{C}-300 \mathrm{~h}$ and $1100{ }^{\circ} \mathrm{C}-300 \mathrm{~h}$, respectively. The morphology of the interface between the TBC and the underlying bond coat was analyzed by Scanning Electron Microscopy (SEM). Results have shown that the fracture toughness of the interface between the bond coat and the top coat decreased as the oxidation conditions become more severe that is the temperature and/or to a lesser extent the exposure time is increased. Simultaneously, the thickness of the thermally grown oxide (TGO) generated on top of the aluminum reservoir bond coat increases as well. The TGO is a "double layer" oxide successively composed of a first scale of $\mathrm{Al}_{2} \mathrm{O}_{3}$ close to the bond coat and a second scale of $\mathrm{CoCrNiO}$ close to top coat. In addition, it was also found that the possible thermally activated spallation of APS TBC's system occurs in the zone of the TGO layer, especially within the CoCrNiO oxide scale. Consequently damage of APS systems is shown to initiate at the interface through complex mechanism of delamination in relation with both the toughness and the microstructure of the interface. In order to inhibit the growth of the detrimental $\mathrm{CoCrNiO}$ oxide and in turn favors the development of a dense and stable alumina scale, a Supersonic Fine Particles Bombarding (SFPB) method was used to optimize the quality of APS coating.
\end{abstract}

Keywords:

APS (Atmospheric Plasma Spray)

TBC (thermal barrier coating)

Interfacial indentation

TGO (thermally grown oxide)

Interfacial fracture toughness

Supersonic Fine Particles Bombarding (SFPB)

\section{Introduction}

TBCs (thermal barrier coating) are widely used in components operating at high temperature such as gas turbines and aero-engines. The objective of TBCs is to protect and insulate the underneath metallic parts in order to permit specific design able to be run under optimized high temperatures, thus increasing turbine efficiency. Even though TBC systems allow superior improvement of component performance $[1,2]$, thermal strains and stresses resulting from transient thermal gradients developed during in-service thermal and mechanical cyclic exposure limit the durability of the multi-material system, often by provoking early cracking and detrimental spallation of the protective deposit.

The adherence properties of TBC systems usually decrease following exposure at high temperature because of the growth of a TGO (thermally grown oxide) layer in service and the development of residual stress in the TBC $[3,4]$. This layer, acting as a diffusion barrier, generally exhibits

\footnotetext{
* Corresponding author.

E-mail address: liuyankuan314@163.com (Y. Liu).
}

roughly parabolic growth kinetics, until either out-of-plane or in-plane cracking develops, which stands as the onset to the degradation usually through the detachment and ejection of TBC or TBC plus TGO particles. Consequently, this spallation-induced damage strongly limits the lifetime of the TBC systems. As a matter of fact, the interfacial toughness, indicating the capacity of the system to resist to the initiation and propagation of cracks throughout the TGO or at the interface that the TGO develops either with the top coat or the bond coat, is one of the most important factors to assess for the durability of TBC systems [5]. According to different manufacturing approaches and various aging conditions, several specific interfacial toughnesses and spallation location in relation with microstructural details such as rumpling, barbules development, have been investigated [6,7].

Following aging, different crack locations, mainly controlled by the bond coat composition and the top coat deposition methods, are identified. In sol-gel TBC, defects occur within the YSZ (Yttria-Stabilized Zirconia) layer as well as at the bond coat/TGO interface or even within the TGO itself [6]. Meanwhile, the EB-PVD (Electron Beam Physical Vapor Deposition) TBC delaminates mainly between the bond coat/TGO interface for TGO layers thicker than circa $3 \mu \mathrm{m}$ and at the TGO/top coat 
interface for thinner TGO [8], In this paper, a complete TBC system has been developed including not only the top coat but also the bond coat both deposited using the APS (Atmospheric Plasma Spraying) method. In some cases and for the purpose of comparison, an additional step of surface modification, namely Supersonic Fine Particles Bombarding (usually $\mathrm{SiO}_{2}$ particles) (SFPB) has been implemented on bond coat prior to the final deposition of the top coat. As the consequence, grain refinement and enhancement of the dislocation density occurring in APS-SFPB barriers, provide short-circuit for the diffusion of aluminum, thus changing the nature of the TGO as compared to that grown on simple APS barriers.

The TBC system produced either by APS or APS-SFPB is a layered multi-material. The system is composed of the nickel base superalloy substrate, a sub-layer (bond coat) of MCrAlY and a ceramic layer (top coat) of YSZ. The main degradation of this type of system is due to an alteration of the adhesion at interfaces of the thermal barrier as a consequence of isothermal oxidation (physical-chemical) or cyclic oxidation (thermo-mechanical) [9].

In this paper, specimens have been oxidized according to various isothermal aging conditions in order to grow oxide scales with different thicknesses and different proportions of $\mathrm{Al}_{2} \mathrm{O}_{3}$ versus $\mathrm{CoCrNiO}$. Using interfacial indentation test $[10,11,12]$, interfacial toughness of specimens relative to the different aging treatments were explored respectively.

\section{Experimental}

Substrates are cylinders with a diameter of $25 \mathrm{~mm}$ and a thickness of $5.6 \mathrm{~mm}$. The substrate material is a nickel based alloy-718, whose chemical composition and physical properties are given in Tables 1 and 2 respectively. CoCrAlY powders were used to prepare the bond coat whose thickness is $220 \mu \mathrm{m}$. CoCrAlY is composed of $23 \mathrm{wt} \%$ of chromium (Cr), $13 \mathrm{wt} \%$ of aluminum (Al), $0.5 \mathrm{wt} \%$ of yttrium (Y) and remaining cobalt (Co). YSZ powders were used to deposit the top coat, the thickness of this layer is $330 \mu \mathrm{m}$. The typical equilibrium YSZ components are $93 \mathrm{wt} \%$ and $7 \mathrm{wt} \%$ of $\mathrm{ZrO}_{2}$ and $\mathrm{Y}_{2} \mathrm{O}_{3}$ respectively.

The equipment used to prepare the TBC is the Control System APS 3710 model manufactured by PRAXAIR, US. To ensure a consistent and accurate distance and projection speed, the model 2400M six axes robot automatic hand manufactured by $\mathrm{ABB}$ was utilized for spraying. The spraying parameters are given in Tables 3 and 4:

Isothermal oxidation tests may be classified into four (4) groups, all conducted in the same furnace. Two (2) groups are carried out for $100 \mathrm{~h}$ exposure time and oxidation temperatures of $1050^{\circ} \mathrm{C}$ and $1100{ }^{\circ} \mathrm{C}$, respectively. The other two (2) groups correspond to a longer exposure time, i.e. $300 \mathrm{~h}$ and to the same oxidation temperatures that is, $1050{ }^{\circ} \mathrm{C}$ and $1100{ }^{\circ} \mathrm{C}$, respectively.

The cross sections of the coated specimens were investigated by Scanning Electron Microscopy (SEM) to reveal details of the morphology, the possible damage and the overall microstructure. The coatings were evaluated by X-ray diffraction using a Bruker D8 Advance with $\mathrm{Cu}-\mathrm{K} \alpha$ radiation to detect and analyze the different phases. The hardness and Young's modulus values of the coatings (bond coat and top coat) were obtained by using a CSM Indentation Tester and nano-indenter (Berkovich indenter).

For bi-materials, a simple model basically based on a rule of mixtures to quantitatively measure the apparent toughness of the interface, is proposed in [13] for hard coatings. It is shown that the apparent

Table

Weight percent composition of nickel based alloy-718.

\begin{tabular}{lllllllllll}
\hline Alloy & $\mathrm{C}$ & $\mathrm{Cr}$ & $\mathrm{Mo}$ & $\mathrm{Fe}$ & $\mathrm{Nb}$ & $\mathrm{Ti}$ & $\mathrm{Al}$ & $\mathrm{P}$ & $\mathrm{B}$ & $\mathrm{Ni}$ \\
\hline Ni-718 & 0.125 & 18 & 2.8 & 18 & 5.4 & 1 & 0.5 & 0.006 & 0.004 & Balance \\
\hline
\end{tabular}

Table 2

Physical properties of the nickel based alloy-718

\begin{tabular}{lll}
\hline Alloy & Young's modulus & Poisson's coefficient \\
\hline Ni-718 & $204 \mathrm{GPa}$ & 0.3 \\
\hline
\end{tabular}

toughness of the interface $\left(K_{c a}\right)$ can be calculated by using the following formula:

$K_{c a}=0.015 \frac{P_{c}}{a_{c}^{3 / 2}}\left(\frac{E}{H}\right) I^{1 / 2}$

where: $P_{c}$ is the critical value (in Newton) of the load $P$ exerted using Vickers indentation at the interface between the two materials of the system and $a_{c}$ is the critical crack size (in meter). They both correspond to the values of load and crack size related to the initiation of cracking at the interface due to indentation.

The value of the ratio $\left(\frac{E}{H}\right)_{I}^{1 / 2}$ relative to the interface between the bond coat and the top coat is given by the following equation:

$$
\left(\frac{E}{H}\right)_{I}^{1 / 2}=\frac{\left(\frac{E}{H}\right)_{S}^{1 / 2}}{1+\left(\frac{H_{S}}{H_{T C}}\right)^{1 / 2}}+\frac{\left(\frac{E}{H}\right)_{T C}^{1 / 2}}{1+\left(\frac{H_{T C}}{H_{S}}\right)^{1 / 2}}
$$

where subscripts $S$ and TC stand for substrate (bond coat) and top coat (ceramic layer), respectively.

The methodology relies on the determination of the threshold force or critical load $P_{c}$ required to initiate a crack with a critical size $a_{c}$. If the applied load is lower than $P_{c}$, only the indent resulting from the indentation is observed. If it is higher than $P_{c}$, a crack originating from the indent is formed. The length of the crack increases with the applied load. For very high load, the complete TBC delamination can occur. Then, from the values of $P_{c}$ and crack length, the apparent interfacial toughness $\left(K_{c a}\right)$ is calculated using Eq. (1) with the value of $\left(\frac{E}{H}\right)_{I}^{1 / 2}$ determined from Eq. (2). The method employs a pyramidal indenter and can be applied for a large range of coating thicknesses (greater than $100 \mu \mathrm{m}$ ). Typically, it is specifically used for investigating adhesion of TBC systems [14]. For one specimen on a given treatment condition, each indentation load $P$ generates a square-shaped indent imprint with diagonal $b$ and, if any (when $P \geq P_{c}$ ) a crack with size $a\left(a \geq a_{c}\right)$. Four (4) to five (5) indentations were performed for each load to be as representative as possible and minimize error. Note that to transpose the approach developed in [13] for bi-materials to the case of TBC systems, the thickness of the TGO on which the indentation is performed can be considered much lower than the size of the imprint. The influence of the TGO is thus reasonably neglected [7], which is perfectly justified for most cases including as-received condition, all oxidations at $1050{ }^{\circ} \mathrm{C}$ and $100 \mathrm{~h}$ oxidation at $1100^{\circ} \mathrm{C}$ and to a lower extent for the most time and thermally activated oxidation $\left(1100^{\circ} \mathrm{C} / 300 \mathrm{~h}\right)$. In addition, the method does not take into account the possible metallurgical evolution of both the bond coat and the TBC during high temperature exposure. However, at least in the frame of the approach essentially comparative developed in the paper and as far as the interface is only involved in the mechanical response

Table 3

Parameters for preparing the CoCrAlY bond coat

\begin{tabular}{lll}
\hline Item & Gas & Value \\
\hline Primary gas/PSI & $\mathrm{Ar}$ & 60 \\
Secondary gas/PSI & $\mathrm{He}$ & 120 \\
Carrier gas/PSI & $\mathrm{Ar}$ & 40 \\
Current/A & & 835 \\
Voltage/V & & 38 \\
Spray distance/mm & & 85 \\
Gun moving velocity/mm/s s $^{-1}$ & & 450 \\
Powder source speed/RPM & & 3.5
\end{tabular}


Table 4

Parameters for preparing the YSZ top coat.

\begin{tabular}{lll}
\hline Item & Gas & Value \\
\hline Primary gas/PSI & $\mathrm{Ar}$ & 60 \\
Secondary gas/PSI & $\mathrm{He}$ & 120 \\
Carrier gas/PSI & $\mathrm{Ar}$ & 30 \\
Current/A & & 860 \\
Voltage/V & & 38.7 \\
Spray distance/mm & & 72 \\
Gun moving velocity/mm/s s $^{-1}$ & & 250 \\
Powder source speed/RPM & & 4.0 \\
\hline
\end{tabular}

of the system, the method can be beneficially used to estimate the apparent interfacial toughness. Quantitative approach is derived by plotting two lines, i.e. $\ln P$ versus $\ln b$ (the so-called hardness line) and $\ln P$ versus lna (the so-called induced-crack line). The intercept between the two lines gives the critical load $P_{c}$ and the critical crack size $a_{c}$. The values of $a$ and $b$ are initially measured by SEM (Fig. 1).

\section{Results and discussion}

Hardness and Young's modulus of both the bond coat and the top coat tested by Berkovich method are shown in Table 5. They are issued from images and elastic force-displacement curve as shown for the top coat in Fig. 2(a) and (b). The principle of the measurement is based on the depth-controlled indentation of the material. Once the fixed penetration (here $2 \mu \mathrm{m}$ ) is reached, the load is kept constant for a short time (in our case under a force of $460 \mathrm{nN}$ ), giving rise to a slight material relaxation. The force is then released to retrieve the elastic strain produced by the indentation. The hardness and Young's modulus are respectively appreciated by measuring the size of the indent imprint and the slope of the elastic curve upon stress release.

The linear relationship between $(\ln b)$ and $(\ln P)$ (Fig. 3) showing a slope close to 0.5 (calculated to be 0.485 ) is in good agreement with the general standard formula relating the Vickers hardness $(H V)$ of bulk materials to the ratio between the applied load $P$ and the square of the diagonal length $d^{2}$.

The general formula of the Vickers hardness is:

$H v=\frac{1.8544 F}{d^{2}}$

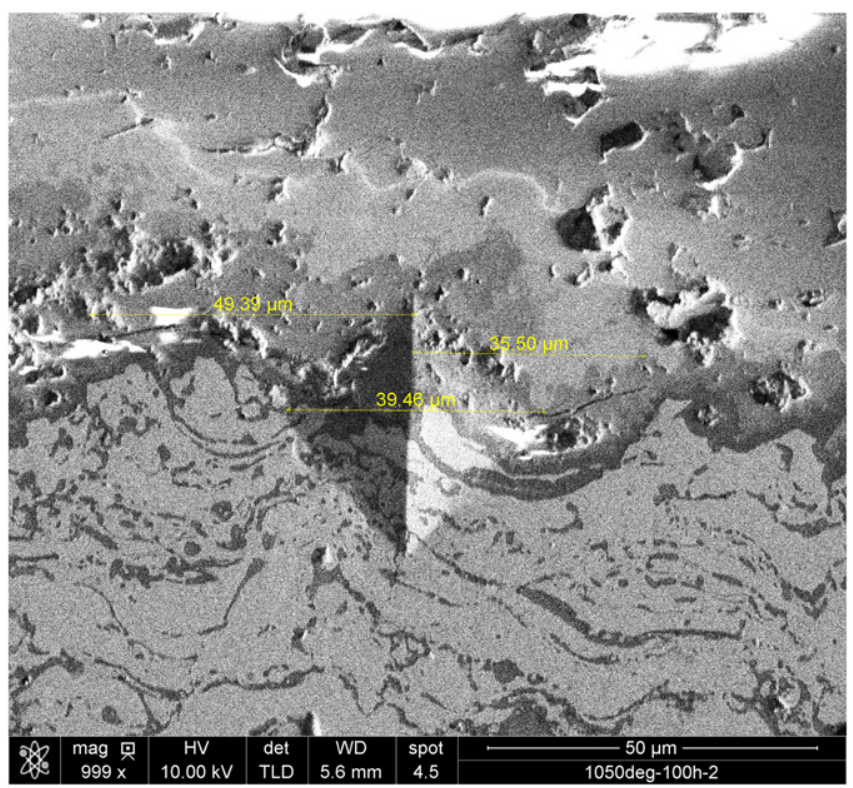

Fig. 1. Principle for measuring $2 \mathrm{a}$ (crack size) and $2 \mathrm{~b}$ (indentation imprint size) by Scanning Electron Microscopy.
Table 5

Values of hardness and Young's modulus measured by nano-indentation (Berkovich).

\begin{tabular}{lll}
\hline Layer & Hardness (HV) & Young's modulus (GPa) \\
\hline Top coat & 587 & 73.5 \\
Bond coat & 485 & 125.5 \\
\hline
\end{tabular}

where $F$ is the applied load for the indentation and $d$ is the diagonal length of the indentation imprint, (note that in the case presented here $F=P$ and $d=b$ ).

so : $\quad d^{2}=\frac{1.8544 F}{H v}$

giving:

$\ln (d)=\frac{1}{2}(F)+\frac{1}{2} \ln \left(\frac{1.8544}{H v}\right)$

then:

$\ln (b)=\frac{1}{2}(P)+K$

with $K a$ constant $\quad K=\frac{1}{2} \ln \left(\frac{1.8544}{H v}\right)$

In Fig. 3 is plotted the curve gathering the whole set of hardness data obtained for the whole bunch of specimens, respectively aged and nonaged, the so-called master curve. As this master curve basically

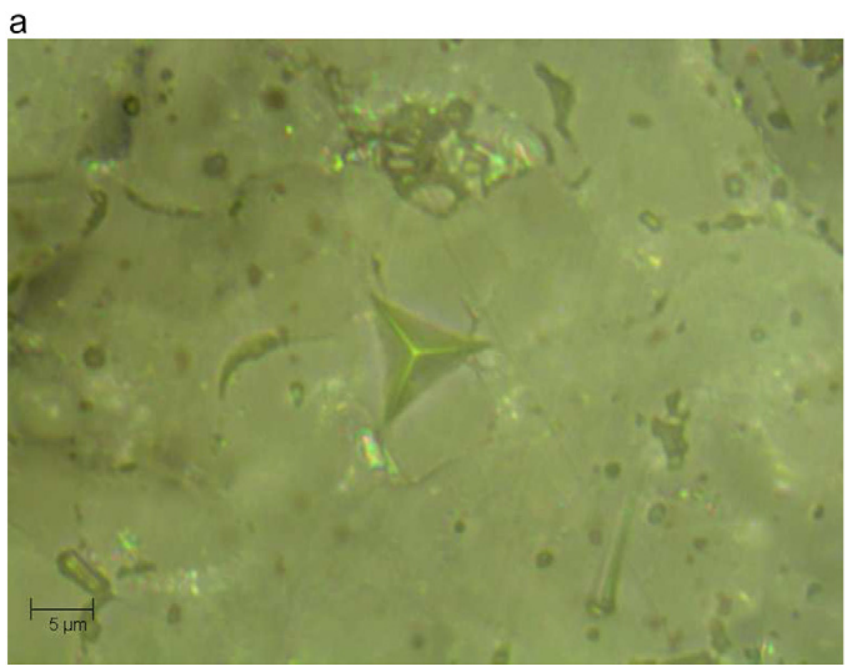

b

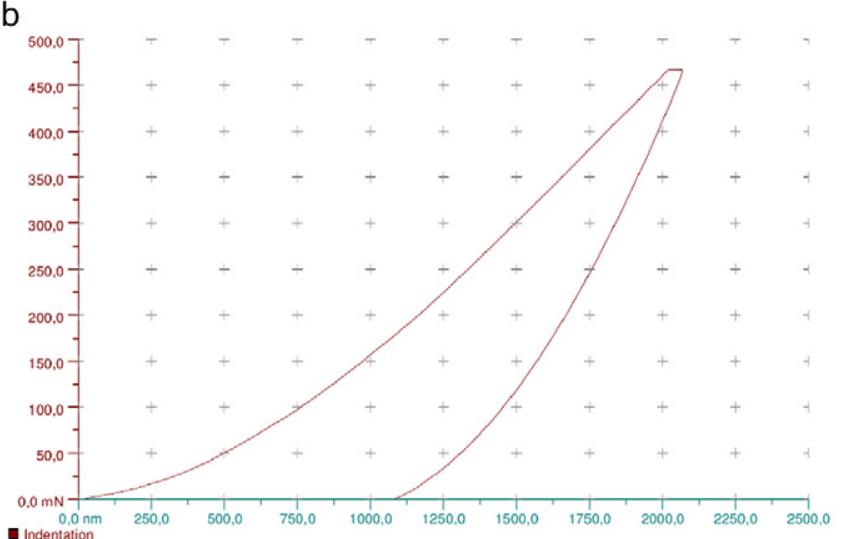

Fig. 2. Imprint of the nano-indentation (Berkovich) (a), and load-penetration and relaxation curve in the top coat (b). 


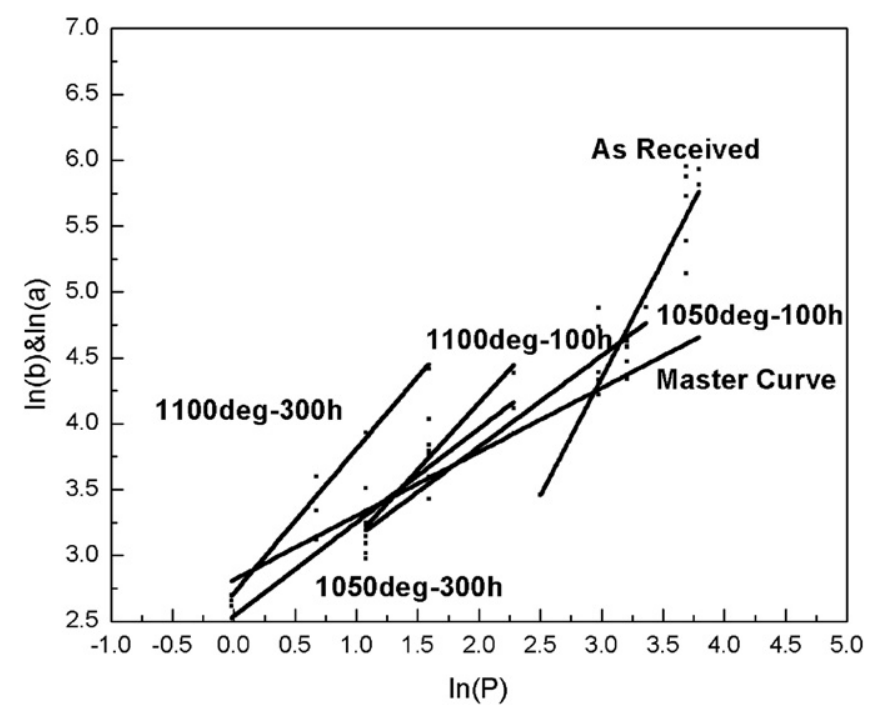

Fig. 3. Graphic determination of critical loads causing delamination of the thermal barriers.

corresponds to a typical hardness curve, the slope (roughly 0.5 ) is unchanged independently of the aging condition. It was also confirmed that the position of the straight line is independent of the aging temperature and holding time. Both conditions justify to gather all values on a same master curve [8]. As well, crack curves $(\ln a)$ versus $(\ln P)$ giving the evolution of the load-induced crack length for the various oxidation conditions tested are superimposed to the graph. Note that for given oxidation time and temperature, that is a given oxidation thickness, the variation of the length $a$ of the indentation-induced crack versus the applied load $P$ also fits a single regression line in a $\log$-Log scale. This can beneficially serve to evaluate the critical load $P_{c}$ necessary to initiate interfacial detachment. The principle for the graphical determination of this critical load is given in Fig. 3 where both the $(\ln b)-(\ln P)$ and the various $(\ln a)-(\ln P)$ lines corresponding to all oxidation conditions are plotted. The intercept between the master curve (hardness curve) and the crack curves discriminates the two domains where the applied load is respectively, i) too low to initiate interfacial cracking, ii) high enough to provoke the initiation and the propagation of an interfacial crack. This procedure can be repeated as often as necessary to determine graphically the critical load for each condition, i.e. each oxide thickness. For the cases shown in Fig. 3, results in terms of line slope and linearity are given in Table 6 and critical load $P_{c}$, critical crack size $a_{c}$, apparent toughness $K_{c a}$ and oxide thickness $\zeta$ are given in Table 7 . As expected, the critical load to efficiently indent the interface between the CoCrAlY bond-coat and the YSZ top-coat and subsequently produce a measurable interfacial crack, as well as the interfacial toughness, decrease with the severity of the high temperature exposure (Fig. 4) and the thickness of the TGO that grows according to a thermally activated process (Fig. 5). It can be noticed that the values of the interfacial toughness for all conditions are significantly lower in the case of APS TBC than for EB-PVD as reported in [8] suggesting a lower resistance to crack initiation and propagation for APS systems.

Table 6

Equations of curves under different conditions.

\begin{tabular}{lll}
\hline Conditions & Equations & $\begin{array}{l}\text { Linearity (correlation } \\
\text { coefficient R values) }\end{array}$ \\
\hline Master curve & $\ln (b)=0.485 \ln (P)+2.817$ & 0.966 \\
As-received & $\ln (a)=1.783 \ln (P)-1.000$ & 0.834 \\
$1050{ }^{\circ} \mathrm{C}-100 \mathrm{~h}$ & $\ln (a)=0.690 \ln (P)+2.446$ & 0.963 \\
$1100{ }^{\circ} \mathrm{C}-100 \mathrm{~h}$ & $\ln (a)=1.018 \ln (P)+2.124$ & 0.880 \\
$1050{ }^{\circ} \mathrm{C}-300 \mathrm{~h}$ & $\ln (a)=0.712 \ln (P)+2.540$ & 0.848 \\
$1100{ }^{\circ} \mathrm{C}-300 \mathrm{~h}$ & $\ln (a)=1.094 \ln (P)+2.715$ & 0.981 \\
\hline
\end{tabular}

Table 7

Critical load, critical crack size, interfacial toughness and thickness of the TGO for the different oxidation conditions.

\begin{tabular}{lllll}
\hline Conditions & $P_{c}(\mathrm{~N})$ & $a_{c}(\mu \mathrm{m})$ & $K_{a c}\left(\mathrm{MPa} \cdot \mathrm{m}^{1 / 2}\right)$ & $\zeta(\mu \mathrm{m})$ \\
\hline $\begin{array}{l}\text { As-received } \\
1050 \mathrm{deg}-\end{array}$ & 18.935 & 69.69 & 2.14 & 0 \\
$\quad 6.110$ & 40.25 & 1.57 & 5.79 \\
$\begin{array}{l}1100 \mathrm{~h} \text { deg- } \\
\quad 100 \mathrm{~h}\end{array}$ & 3.670 & 31.41 & 1.38 & 9.64 \\
$\begin{array}{l}1050 \mathrm{deg}- \\
\quad 300 \mathrm{~h}\end{array}$ & 2.718 & 25.84 & 1.36 & 9.17 \\
$\begin{array}{l}1100 \mathrm{deg}- \\
300 \mathrm{~h}\end{array}$ & 1.182 & 18.14 & 1.01 & 15.1 \\
\hline
\end{tabular}

Besides, the toughness of the YSZ layer is about $1.970 \mathrm{MPa} \cdot \mathrm{m}^{1 / 2}[15]$, which is nearly the same as the interfacial toughness of as-received specimen and higher than those of specimens corresponding to the different aging conditions. This can explain satisfactorily why failure occurs systematically at the interface through a combined process of delamination and spalling but not within the ceramic itself. This type of adhesive failure is favoured at the expense of a purely cohesive failure within the barrier itself because the interface is less resistant to crack initiation and propagation than the YSZ top coat.

Fig. 6 presents the morphology and microstructure of the oxide thermally grown between the bond coat and the top coat following isothermal oxidation at $1050^{\circ} \mathrm{C}$ during $100 \mathrm{~h}$.

The oxide layer (TGO) is composed of two layers, respectively shown in dark (layer 1) and light (layer 2) contrast on the SEM micrograph in Fig. 6. Figs. 7 and 8 show the elemental composition determined by EDS (Energy Dispersive Spectroscopy) for layer 1 and layer 2. The mass ratio of $\mathrm{Al} / \mathrm{O}$ for layer 1 is $50.17 / 42.77$, which is pretty close to the ratio for the stoichiometric alumina $\mathrm{Al}_{2} \mathrm{O}_{3}$ (1.125) suggesting that the main component in layer 1 is $\mathrm{Al}_{2} \mathrm{O}_{3}$, formed during high temperature exposure using the aluminum contained in the bond coat reservoir. In layer 2, in addition to $\mathrm{Al}$ and $\mathrm{O}$, large amounts of $\mathrm{Co}, \mathrm{Cr}$ and $\mathrm{Ni}$ are identified, giving rise to the occurrence of a complex thermally grown oxide. The formation of such oxide cannot be due to the exhaustion of $\mathrm{Al}$, as the temperature and the exposure time are both too low to generate the full depletion of the $\mathrm{Al}$ reservoir.

This is because, before the final formation of the $\mathrm{Al}_{2} \mathrm{O}_{3}$ oxide layer, the elements $\mathrm{Co}, \mathrm{Ni}$ and $\mathrm{Cr}$ were filtered through $\mathrm{Al}_{2} \mathrm{O}_{3}$ in the ceramic layer and with the increase of heating time, the elements have had an oxidation reaction thus generating a $\mathrm{CoCrNiO}$ layer.

Fig. 9 details the elements distribution at the surface of a failed specimen as revealed by Energy Dispersive X-ray Spectroscopy (EDS). Only a spot in the centre of the image, showing nickel, is relative to the bond

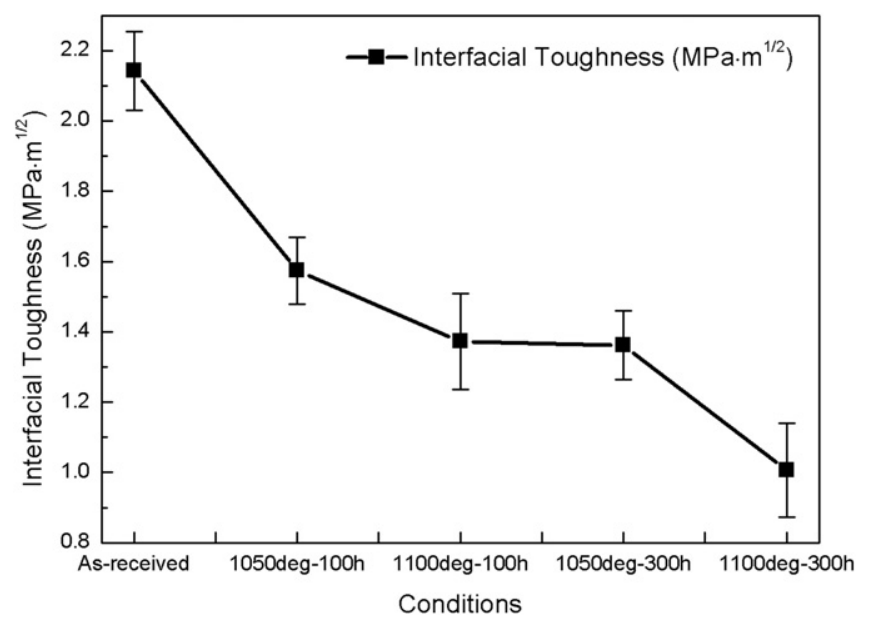

Fig. 4. Evolution of the interfacial toughness as a function of aging oxidation. 


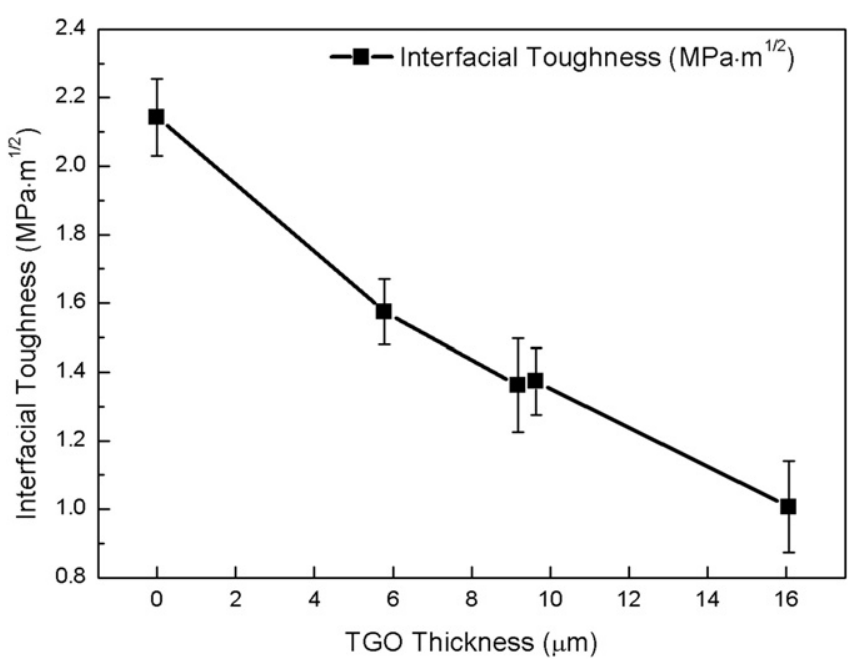

Fig. 5. Evolution of the interfacial toughness as a function of the oxide thickness.

coat. Note that elements constituting the top coat, namely yttrium and the zirconium, are rarely observed except concomitantly on very localised zone. $\mathrm{Al}_{2} \mathrm{O}_{3}$ and $\mathrm{CoCrNiO}$ oxides, mainly cover the surface of the spalled specimen in a complementary way. Cobalt and chromium can be observed on most parts of the image. Aluminum seems also rather homogeneously distributed, but only the zone around the centred spot is intense. The rest of the observed aluminum distribution can be the result of electron-specimen interactions where the thickness of the $\mathrm{CoCrNiO}$ is not high enough to efficiently limit the phenomenon.

Fig. 10 shows the example of a specimen where crack is located within the $\mathrm{CoCrNiO}$ layer. Actually, indentation is initially applied on the $\mathrm{Al}_{2} \mathrm{O}_{3}$ layer, and as a consequence cracks initiates from the $\mathrm{Al}_{2} \mathrm{O}_{3}$ layer or the $\mathrm{Al}_{2} \mathrm{O}_{3}$ /bond coat interface. However, it ends up almost every time within the $\mathrm{CoCrNiO}$ layer, which suggests that crack propagation is easier in the $\mathrm{CoCrNiO}$ layer than in the $\mathrm{Al}_{2} \mathrm{O}_{3}$ layer.

The SEM images of Fig. 11(a) and (b) showing the exact location of the APS TBC's spallation, correspond to two cracked specimens respectively aged $300 \mathrm{~h}$ at $1050{ }^{\circ} \mathrm{C}$ and $300 \mathrm{~h}$ at $1100{ }^{\circ} \mathrm{C}$. The images show clearly that the spallation occurs in the TGO layer. It initiates and

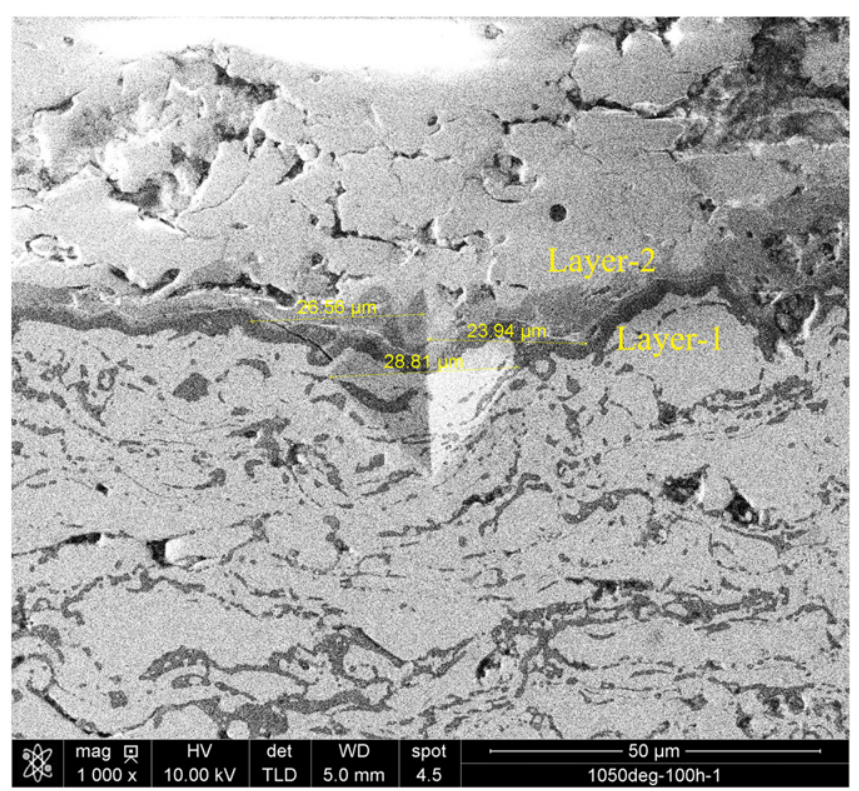

Fig. 6. Oxide morphology.

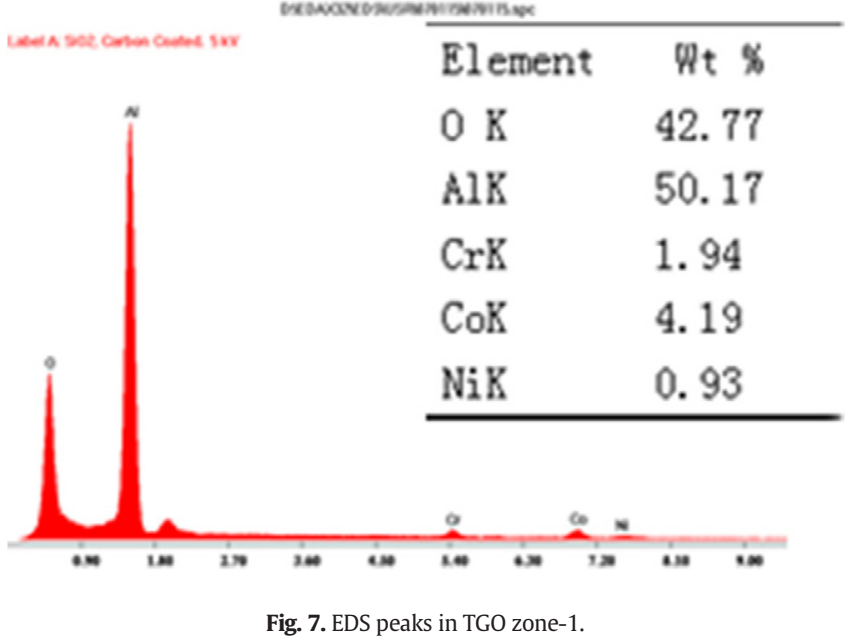

extends within the CoCrNiO layer eventually resulting in a separation of the top coat and the bond coat.

Spallation of APS TBC's system is mainly located within the TGO layer. The results of interfacial toughness show that cracks propagate preferentially in the CoCrNiO. This is the reason why fragments of $\mathrm{CoCrNiO}$ layer remain on most part of the surface of the spalled specimens. The toughness of the $\mathrm{CoCrNiO}$ layer decreases when the aging condition becomes more severe in term of temperature and/or holding time.

Fig. 12(a) and (b) show the TGO morphology after aging $100 \mathrm{~h}$ at $1050^{\circ} \mathrm{C}$ for an APS coating and an APS-SFPB coating, respectively. Contrarily to the case of APS coatings where the thermally grown oxide is a complex multi-layered scale, the TGO in APS-SFPB coatings only consists in a thin, black-contrast $\mathrm{Al}_{2} \mathrm{O}_{3}$ layer. Fine particles bombarding of the bond coat has produced a significant grains refinement and a huge enhancement of dislocation density, which drastically increase the diffusion channels for $\mathrm{Al}$ [16]. It is expected to obtain a more compact and stable oxide layer with a straightforward reduction of the diffusion of $\mathrm{Co}$, Ni and $\mathrm{Cr}$. Fig. 13 shows the XRD patterns (X-ray diffraction) in the TGO region for specimens oxidized $100 \mathrm{~h}$ at $1050{ }^{\circ} \mathrm{C}$. Note that no $\mathrm{Ni}(\mathrm{Cr}, \mathrm{Al})_{2} \mathrm{O}_{5}$ is identified within the APS-SFPB coating.

The optimized morphology and composition of the oxide scale grown at the interface between the bond coat and the top coat should unambiguously improved the lifetime of the TBC upon thermal cycling. The interfacial toughness should as well be increased by such a promising treatment, leading to a better resistance to spallation and degradation. Lifetime of APS and APS-SFPB coatings were tested in cyclic conditions, following successive 30 minute heating at $1050{ }^{\circ} \mathrm{C}$ and

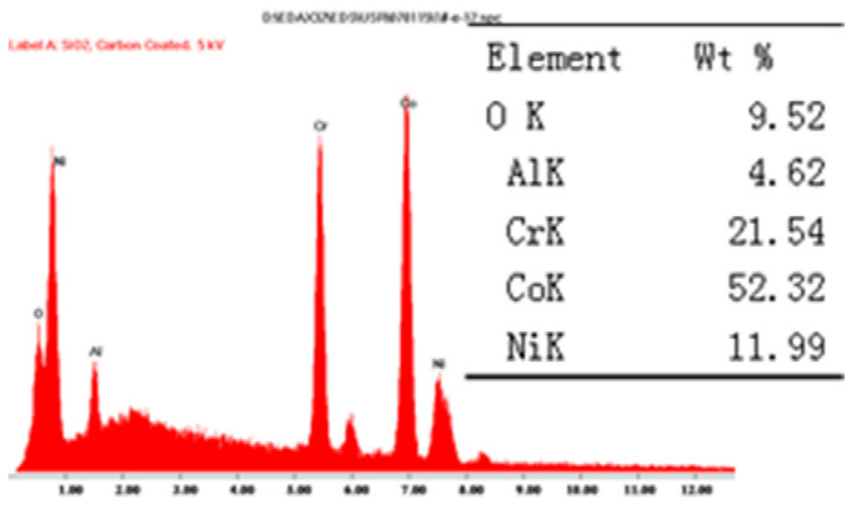

Fig. 8. EDS peaks in TGO zone-2. 


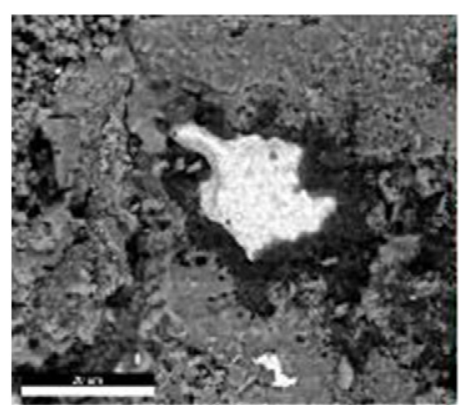

(a)

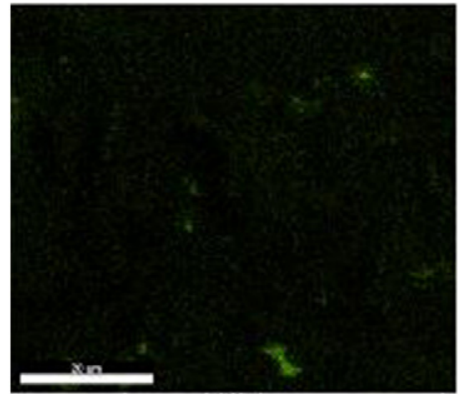

(d)

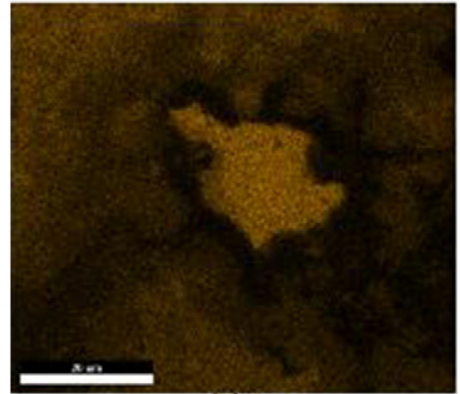

$(\mathrm{g})$

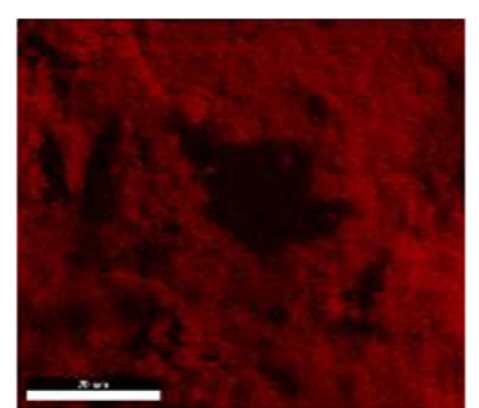

(b)

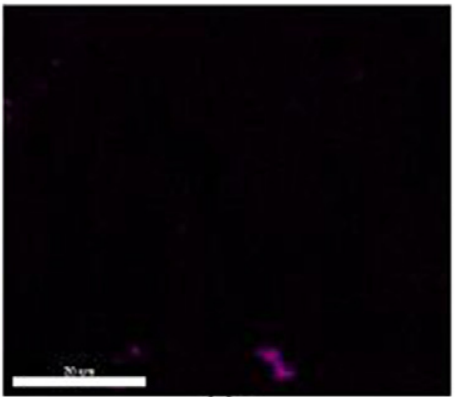

(e)

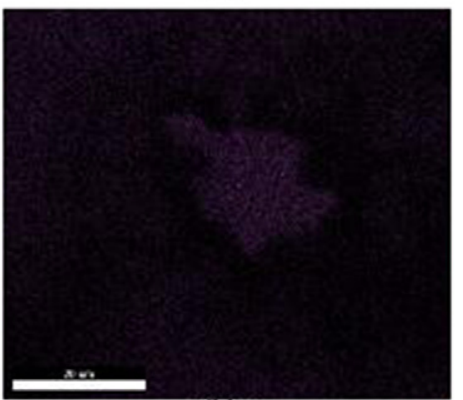

(h)

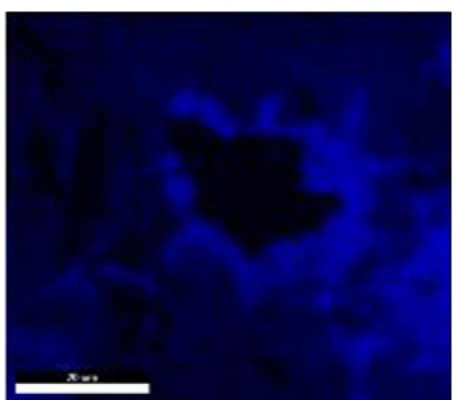

(c)

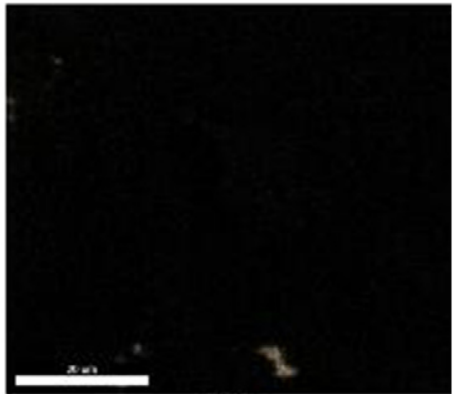

$(\mathrm{f})+$

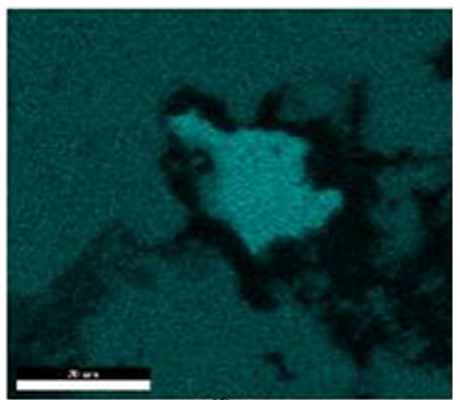

(1)

Fig. 9. SEM image and EDS map of a failed specimen's surface after isothermal oxidation at $1100{ }^{\circ} \mathrm{C}-300 \mathrm{~h}$. (a) SEM image, (b) oxygen, (c) aluminum, (d) yttrium, (e) phosphorus, (f) zirconium, (g) chromium, (h) manganese, (i) cobalt.

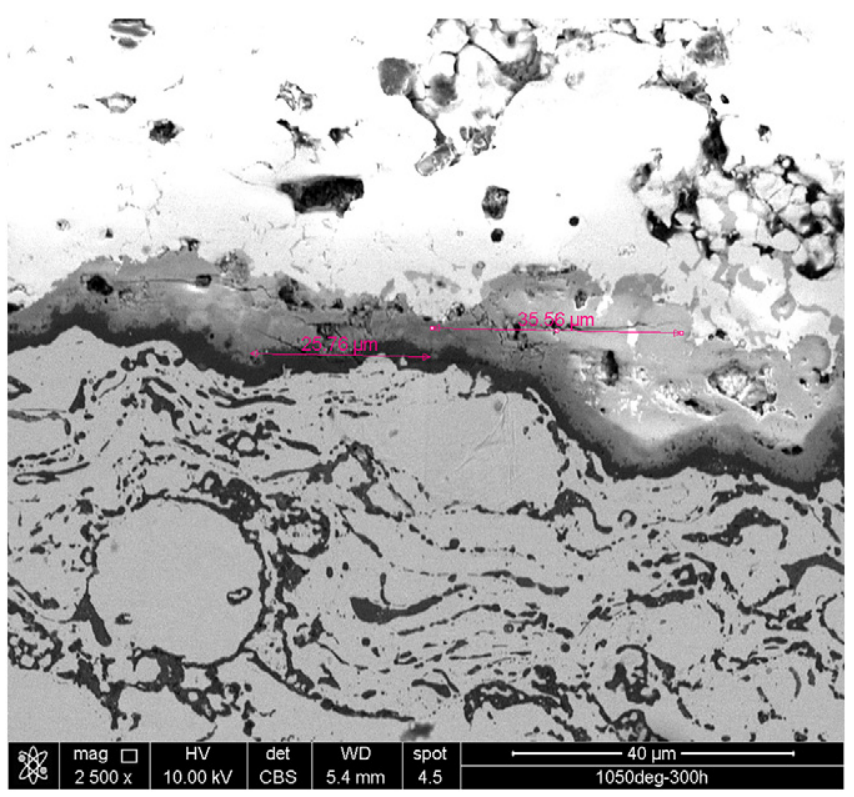

Fig. 10. An example of the crack location for a specimen aged $300 \mathrm{~h}$ at $1050^{\circ} \mathrm{C}$ (indentation load of $300 \mathrm{~g}$ ). subsequent cooling by pulsed air for $5 \mathrm{~min}$. Fig. 14 shows macro-photographs of the failure for TBCs processed by simple APS and APS-SFPB. The number of cycles to failure for the APS coating is 230 where the TBC fully detaches from the substrate, indicating a sudden and entire spallation of the barrier. For the APS-SFPB coatings, the numbers of cycles to failure is higher, reaching 350 , and the mode of failure appears to be slightly different as only cracks are observed at this stage, the barrier remaining partly adherent to the substrate in this case.

\section{Conclusion}

Interfacial indentation has been employed to address interfacial adhesion and derive interfacial toughness in TBC (thermal barrier coatings) systems produced by Atmospheric Plasma Spray technique, after various isothermal aging, in the temperature range $1050{ }^{\circ} \mathrm{C}-1100{ }^{\circ} \mathrm{C}$ and holding times from 100 to $300 \mathrm{~h}$. As compared to the as-deposited, unaged TBC, it is shown that the toughness degrades with both the oxidation time and temperature, remarkably decreasing quasi-linearly with the thickness of the TGO (thermally grown oxide) that develops upon holding at high temperature. Typically for APS processed TBC, the TGO is a multi-scale oxide composed of successive layers of $\mathrm{Al}_{2} \mathrm{O}_{3}$ and $\mathrm{CoCrNiO}$. It is shown that the measured interfacial toughness for aged TBC is systematically lower than the toughness of the top coat resulting in a preferential path for crack-induced spallation along the 

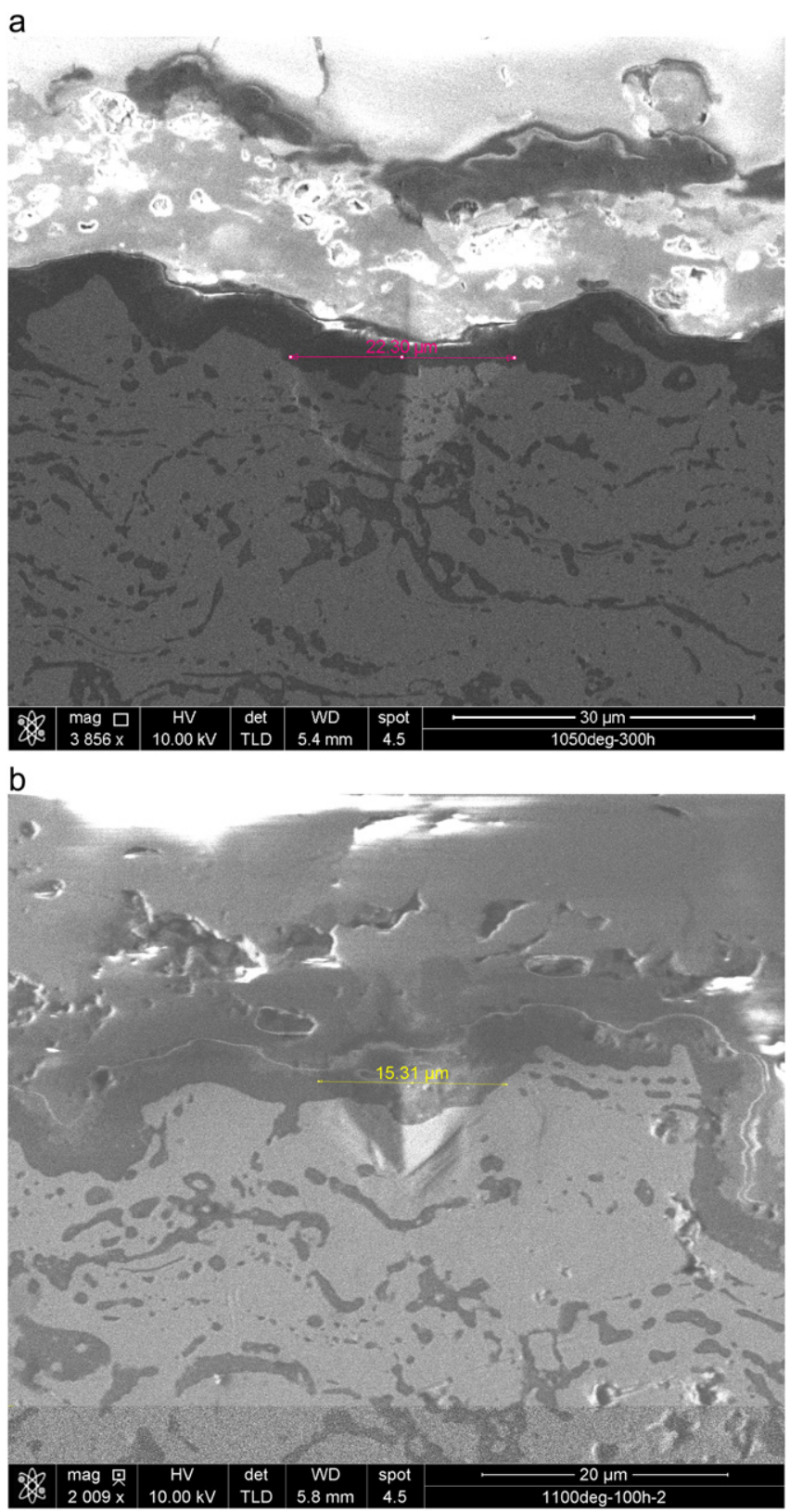

Fig. 11. SEM image of cracked specimens, following 300 hour oxidation at $1050^{\circ} \mathrm{C}$ (a) and 300 hour oxidation at $1100^{\circ} \mathrm{C}(\mathrm{b})$.

TGO rather than within the ceramic top coat itself. More precisely, the exact location for crack propagation is mainly confined in the $\mathrm{CoCrNiO}$ oxide scale. This suggests that limiting the growth of the $\mathrm{CoCrNiO}$ scale would enhance the resistance of the system to spallation. This can be efficiently achieved by post-processing the bond coat, prior to the ceramic top coat deposition, using a promising newly developed technique consisting in bombarding the surface with fine $\mathrm{SiO}_{2}$ particles to create preferential diffusion channels for aluminum, increasing the alumina-forming capability of the system. The resulting occurrence of a dense, compact and stable alumina scale allows to inhibit the growth of $\mathrm{CoCrNiO}$ and to significantly improve the quality of both the interface and the overall system. It is proved by measuring the number of cycles to failure upon cyclic oxidation of such processed TBCs, that the lifetime can be significantly increased. Work is in progress to correlate the lifetime to the interfacial toughness that can be straightforwardly measured using interfacial indentation as well.

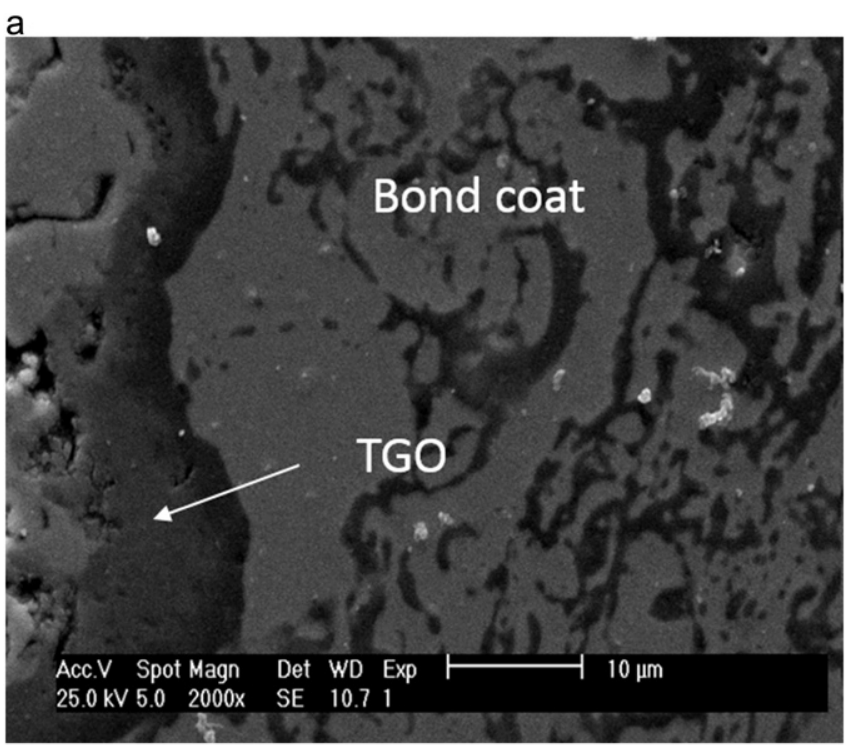

b

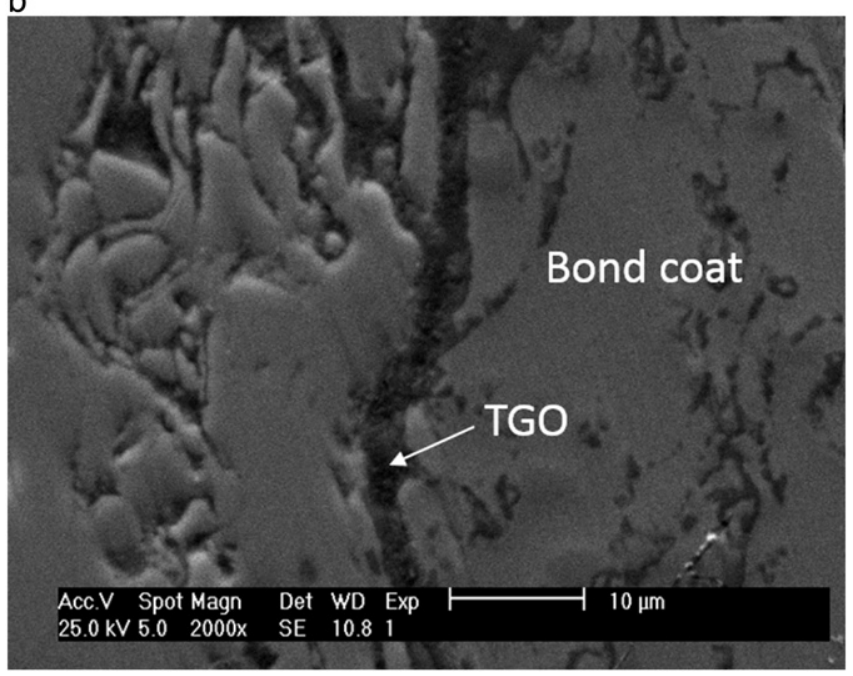

Fig. 12. (a). TGO morphology following 100 hour oxidation at $1050{ }^{\circ} \mathrm{C}$ for APS specimen (a) and APS-SFPB specimen (b).

\section{Acknowledgements}

This work was financially supported by the projects of National Natural Science Foundation of China (51501222), Civil Aviation Authority Science and Technology Program (MHRD20160106),Provincial and Ministerial Scientific Research Institution Opening Fund of CAUC (Research on Reliability Evaluation Technology of Non - Destructive Testing Based on POD) and Ressourcement Carnot M.I.N.E.S 2013 at Institut Clément Ader.

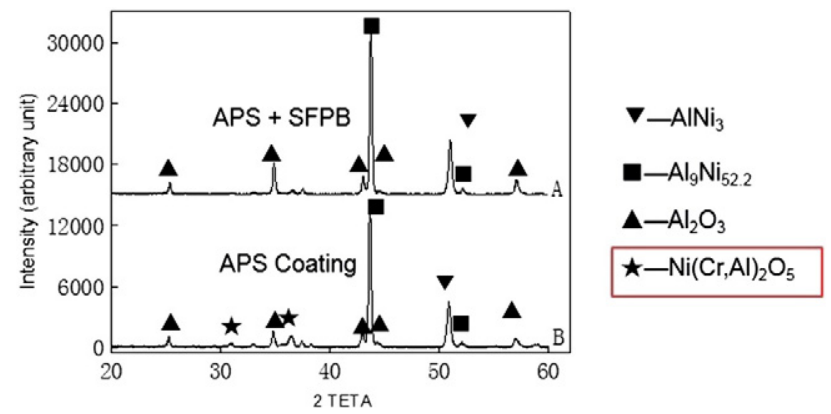

Fig. 13. XRD patterns for APS and APS-SFPB coatings after 100 hour oxidation at $1050{ }^{\circ} \mathrm{C}$. 
a

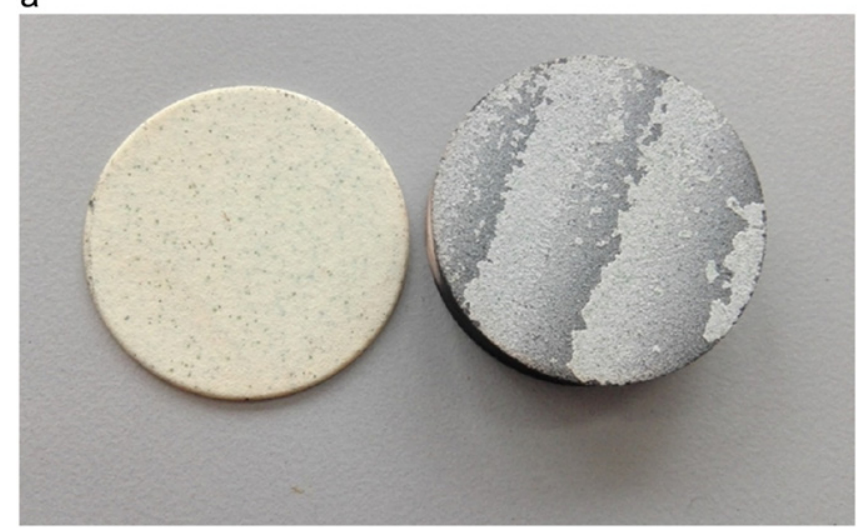

b

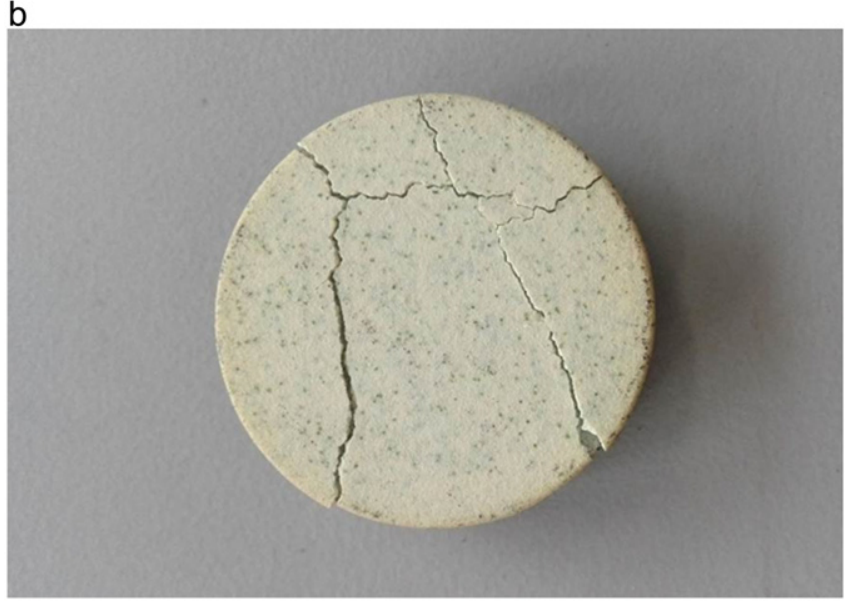

Fig. 14. Failure of an APS specimen after 230 cycles (a), and an APS-SFPB specimen after 350 cycles (b) (diameter of specimens is $25 \mathrm{~mm}$ ).

\section{References}

[1] N. Padture, M. Gell, E.H. Jordan, Thermal barrier coatings for gas-turbine engine applications, Science 296 (2002) 280-284.

[2] B. Goswami, K. Ray Ashok, S.K. Sahay, Thermal barrier coating system for gas turbine application-a review, High Temp. Mater. Processes 23 (2004) 73-92.
[3] W.R. Chen, X. Wu, D. Dudzinski, Influence of thermal cycle frequency on the TGO growth and cracking behaviors of an APS-TBC, J. Therm. Spray Technol. 21 (6) (December 2012) 1294-1299.

[4] M. Gupta, K. Skogsberg, P. Nylén, Influence of topcoat-bondcoat interface roughness on stresses and lifetime in thermal barrier coatings, J. Therm. Spray Technol. 23 (12) (January 2014) 170-181.

[5] W.R. Chen, R. Archer, X. Huang, B.R. Marple, TGO Growth and Crack Propagation in a Thermal Barrier Coating, J. Therm. Spray Technol. 17 (5-6) (2008) 858-864 (MidDecember).

[6] L. Pin, V. Vidal, F. Blas, F. Ansart, S. Duluard, J.P. Bonino, Y.L. Maoult, P. Lours, Optimized sol-gel thermal barrier coatings for long-term cyclic oxidation life, J. Eur. Ceram. Soc. 34 (2014) 961-974

[7] J. Sniezewski, V. Vidal, P. Lours, Y.L. Maoult, Thermal barrier coatings adherence and spallation: interfacial indentation resistance and cyclic oxidation behavior under thermal gradient, Surf. Coat. Technol. 204 (2009) 807-811.

[8] Y. Liu, V. Vidal, S. Le Roux, F. Blas, F. Ansart, P. Lours, Influence of isothermal and cyclic oxidation on the apparent interfacial toughness in thermal barrier coating systems, J. Eur. Ceram. Soc. 35 (2015) 4269-4275.

[9] H.M. Tawancy, N. Sridhar, N.M. Abbas, Failure mechanism of a thermal barrier coating system on a nickel-base superalloy, J. Mater. Sci. 33 (1998) 681-686.

[10] D. Choulier, Contribution à l'étude de l'adhérence de revêtements projetés a la torche a plasma. Modélisation et utilisation d'un test d'indentation à l'interface(Thèse de doctorat) Université de Technologie, Compiègne, 1989.

[11] J.L. Vasinonta, A. Beuth, Measurement of interfacial toughness in thermal barrier coating systems by indentation, Eng. Fract. Mech. 68 (2001) S843-S860.

[12] W.G. Mao, J. Wan, C.Y. Dai, J. Ding, Y. Zhang, Y.C. Zhou, C. Lu, Evaluation of microhardness, fracture toughness and residual stress in a thermal barrier coating system: a modified Vickers indentation technique, Surf. Coat. Technol. 206 (2012) $4455-4461$.

[13] D. Chicot, P. Démarécaux, J. Lesage, Apparent interface toughness of substrate and coating couples from indentation tests, Thin Solid Films 283 (1996) 151-157.

[14] L.T. Wu, R.T. Wu, X. Zhao, P. Xiao, Microstructure parameters affecting interfacial adhesion of thermal barrier coatings by the EB-PVD method, Mater. Sci. Eng. A 594 (2014) 193-202.

[15] R. Taylor, J.R. Brandon, P. Morrell, Microstructure, composition and property relationships of plasma-sprayed thermal barrier coatings, Surf. Coat. Technol. 50 (2) (1992) 141-149.

[16] E.P. Busso, J. Lin, S. Sakurai, M. Nakayama, A mechanistic study of oxidation-induced degradation in a plasma sprayed thermal barrier coating system, part II: life prediction model, Acta Mater. 49 (2001) 1529-1536. 